\title{
Participación de la Sociedad Civil en el Marco de la Integración Regional Centroamericana: la experiencia del Foro de Mujeres por la Integración Centroamericana y la Iniciativa Mesoamericana por el Comercio, la Integración y el Desarrollo Sostenible
}

\section{Hloreley Osorio Mercado*, Mario Sánchez González y Marissa Olivares Morales}

\section{Recibido: julio de 2011 / Aceptado: febrero de 2012}

Se devela la dinámica de dos organizaciones civiles regionales que participan en el proceso de integración centroamericana desde espacios institucionalizados o no institucionalizados del sistema: el Foro de Mujeres para la Integración Centroamericana (FMICA), organización insider, miembro del Comité Consultivo del Sistema de Integración Centroamericana (CC-SICA) y la Iniciativa Mesoamericana por el Comercio, la Integración y el Desarrollo Sostenible (Iniciativa CID), organización outsider, que cumple con los requisitos para estar dentro del CC-SICA, pero no lo está.

El FMICA fue beligerante en la dinamización del CC-SICA y la creación de los capítulos nacionales, además consiguió posicionar el enfoque de género en las instituciones del sistema. La Iniciativa CID, con su elevado nivel de investigación, propuesta e incidencia, logró que se incorporaran intereses del sector pesca y temas importantes como los derechos laborales y socio-ambientales.

\footnotetext{
Investigadora del Centro de Análisis Sociocultural-Universidad Centroamericana (CASC-UCA), Correo electrónico: hloreley1@yahoo.com

** Director del Centro de Análisis Sociocultural-Universidad Centroamericana (CASC-UCA), Correo electrónico:m.sanchez@ns.uca.edu.ni

*** Investigadora de la Facultad de Humanidades y Comunicación Social, Universidad Centroamericana. Correo electrónico: marissao@ns.uca.edu.ni
} 
Pese a que desde los espacios consultivos del SICA y plataformas independientes se ejerce cierta influencia en el sistema, probablemente la incidencia sería mayor si se aprovechara el espacio creado en la estructura institucional del SICA. Las fortalezas del FMICA y de la Iniciativa CID tendrían potencial para garantizar un posicionamiento político y un alto nivel de propuesta del CC-SICA.

Palabras clave: participación ciudadana / integración centroamericana / sociedad civil regional / organización insider / organización outsider

\section{Introducción}

El artículo refiere los resultados de la investigación que sobre el tema de la participación de la sociedad civil en el proceso de integración centroamericana, realizó el Centro de Análisis Sociocultural de la UCA. Este estudio es parte del proyecto de Cooperación Interuniversitaria -Universidad José Simeón Cañas de El Salvador, Universidad Centroamericana de Nicaragua y Fundación ETEA de España- alrededor de la situación y perspectivas del proceso de integración regional como instrumento de desarrollo de Centroamérica.

Se pretende responder a dos interrogantes: 1) ¿Cuál ha sido la experiencia del Foro de Mujeres por la Integración Centroamericana (FMICA) y la Iniciativa Mesoamericana por el Comercio, la Integración y el Desarrollo Sostenible (Iniciativa CID) frente al proceso de integración centroamericana? y 2) ¿Qué lecciones aprendidas se pueden extraer respecto a la trayectoria de estas organizaciones civiles en el proyecto integracionista? En la primera interrogante se trata de indagar los roles, intereses, acciones estratégicas, espacios y mecanismos de participación, factores facilitadores y limitantes, así como los resultados alcanzados de dos organizaciones que actúan desde distintas posiciones ideológicas y espacios de participación. Así, el FMICA es una organización miembro del CC-SICA y de los capítulos nacionales y la Iniciativa CID, una organización que realiza incidencia desde su propia plataforma y de manera no permanente, aunque algunas de sus organizaciones son miembros de los capítulos nacionales y del CC-SICA. En la segunda cuestión, se pretendía investigar el significado que tiene el hecho de que las organizaciones de la sociedad civil participen desde distintos espacios, en tanto que son actores que cumplen únicamente con un rol consultivo, de no obligatoriedad en el sistema de integración centroamericana.

Estas interrogantes se relacionan con la institucionalización de la participación de la sociedad civil en el SICA a través de la conformación de cuatro espacios consultivos: Comité Consultivo del Sistema de Integración Centroamericana (CCSICA), Comité Consultivo de Integración Económica (CCIE), Foro de la Sociedad Civil de Ambiente y Desarrollo (FOSCAD) y un mecanismo de participación indirecta en el Tratado Marco de Seguridad Democrática (2001), a través de la SGSICA y del CC-SICA. Pese a que se ha normado la participación de este actor, existen organizaciones como la Asociación Latinoamericana de Organismos de Promoción (ALOP), la Iniciativa CID y la Alianza Social Continental (ASC) que prefieren mantenerse al margen. De acuerdo a Santos Carrillo (2010), el 
enfrentamiento es de tipo político-ideológico, en tanto que acusan al proyecto integracionista de un marcado tono economicista, en detrimento de los sectores empobrecidos, desatendiendo las propuestas de índole social o participativa. Ahora bien, la sociedad civil regional no tiene un interlocutor claro en el SICA.

El enfoque metodológico de la investigación fue cualitativo, de alcance descriptivo. Se realizó análisis documental de estudios sobre la participación de la sociedad civil en el proyecto de integración centroamericana, así como de textos y discursos oficiales acerca del tema de interés. También se aplicaron de 11-13 entrevistas semi-estructuradas por cada levantamiento de experiencia, las cuales estuvieron dirigidas a informantes clave (expertos en el tema, investigadores/as, funcionarios/as de la cooperación y de gobiernos nacionales en los casos en que fue posible), directivos y funcionarios del nivel intermedio de la organización de la sociedad civil (OSC) en estudio.

\section{Marco teórico}

La sociedad civil es un actor principal en el escenario de la gobernabilidad internacional, que cobra fuerza desde la última década del siglo pasado a razón de la dinamización de la democracia como forma de gobierno en Europa del Este y en América Latina. En este contexto, la ciudadanía sobrepasa el carácter jurídico y se convierte, desde el punto de vista político, en una categoría central de la concepción de democracia, en tanto sujeto con derechos políticos, civiles y sociales.

La reactivación del debate sobre la sociedad civil a partir de 1990, coincide, en el caso de Centroamérica, con el relanzamiento de la integración regional a partir del Protocolo de Tegucigalpa (Sistema de Integración Centroamericana, 1991), lo que derivó en la necesidad de institucionalizar la participación de la sociedad civil en el proceso integracionista con la creación del CC-SICA. Más tarde, los diferentes tratados de integración incorporaron la constitución de otros espacios de consulta de la sociedad civil, que estarían adscritos a las secretarías del SICA correspondientes (véase el apartado 3).

En este estudio se define la sociedad civil como un espacio social que comprende las asociaciones $\mathrm{u}$ organizaciones y los movimientos sociales que, actuando a distintos niveles geográficos (local, nacional y regional), son ajenos al Estado, representan intereses diversos y trascienden el universo privado en el que surgen.

Tal como afirma Ortega (2008), el espacio de la sociedad civil es de carácter público, va más allá de la esfera familiar y se convierte en un espacio comunitario; pero es distinto al espacio estatal en el sentido que este último está determinado por la dinámica de la coerción y de la acción de sus aparatos para ejercer su autoridad y regular el ejercicio del poder.

La sociedad civil está caracterizada por ser heterogénea, autónoma del Estado, auto representada, auto organizada y voluntaria. En otras palabras, "la cultura política asociacionista, permite superar las formas tradicionales de clientelismo, populismo y corporativismo presentes en la historia política de América Latina y afianzar por tanto, la ciudadanía como base fundamental de la nueva relación de los ciudadanos con el Estado" (Ortega, 2008, p.12). 
Existen dos enfoques teóricos para el estudio de la sociedad civil: el enfoque liberal y la perspectiva tripartita. El primer enfoque -cuyo máximo exponente es Hegel- se debate entre el enfrentamiento Estado-sociedad civil propio de la democracia liberal, como esferas que pugnan por la primacía y el control de la sociedad. El segundo enfoque, compartido por Cohen y Arato (2000), se refiere a la segmentación analítica de la esfera económica del ámbito de la sociedad civil, quedando configurada esta última como un espacio de interacción social con la economía y el Estado. La visión tripartita nos revela tres tipos de sociedad: sociedad política, sociedad económica y sociedad civil.

Los enfoques teóricos antes esbozados refieren que la sociedad civil tiene como interlocutor y punto de referencia al Gobierno en el marco de la teoría política del Estado-nación. Si esto es así, cabe la pregunta ¿quién es el actor con el que dialoga la sociedad civil dentro del proceso de integración regional? No hay que olvidar que la integración centroamericana es eminentemente intergubernamental, no existen gobiernos regionales propiamente dichos, por lo tanto, la Reunión de Presidentes es el órgano que toma las decisiones de las políticas regionales y la sociedad civil regional (incluyendo las institucionalizadas en Comités y Foros dentro del SICA) sólo participa en la consulta (cuestión que sigue sin ser de obligado cumplimiento por parte del SICA) que hagan los diversos órganos del sistema y otras instancias regionales e internacionales (organismos de cooperación, multilaterales u otros). En concreto, la sociedad civil no tiene, a nivel regional, un interlocutor claro que atienda sus demandas debido a que el proyecto integracionista está presidido por los gobiernos, aunque se reconoce que los espacios consultivos regionales se relacionan con las secretarías a las que están adscritos, secretarías que tienen una función administrativa y burocrática.

Tal como indica Santos (2010, p. 133), la inexistencia de un órgano supranacional que rija el control de la integración centroamericana provoca el predominio de los acuerdos intergubernamentales, la supeditación de la agenda regional a las distintas agendas nacionales y el descontento de algunas organizaciones regionales (aún las que están integradas en los espacios consultivos y foros) que no ven mayor rentabilidad al integrar estos espacios formales por cuanto el proceso consultivo no es de obligado cumplimiento y cuando lo hubiere, no tienen relación directa con los responsables políticos regionales. De allí que la sociedad civil regional decida, a través de sus representantes a escala nacional, entablar diálogo con los gobiernos nacionales, los decisores de la integración regional.

En el caso de los Capítulos Nacionales, el interlocutor según lo normado, es su homólogo en el ámbito regional, el CC-SICA. No obstante, las evidencias empíricas de la dinámica del Capítulo Nicaragua revelan que el diálogo trasciende al CC-SICA, pues se han acercado a las instituciones estatales para el abordaje de la temática referida al Acuerdo de Asociación y cambio climático.

Las funciones de la sociedad civil en los procesos de integración regional han sido estudiadas por Santos (2010). Por un lado, está la lucha de organizaciones civiles en defensa de sus intereses y la consecución de mayores cuotas de participación en la toma de decisiones, a propósito de la democracia. Por otro lado, el tema de la representatividad reduce la capacidad de actuación y la confianza por parte de las instituciones. Todo esto ocurre en un escenario donde todavía hay muestras de 
las formas tradicionales de clientelismo, populismo y corporativismo en América Latina. Por consiguiente, tenemos una sociedad política que controla la mayoría de los procesos y que desconfía de la labor complementaria y legitimadora (no sustitutiva) que ofrece la colaboración civil y carece de voluntad para implementar estrategias participativas.

Aún cuando hay cierto interés y a la vez temor por la inclusión de la sociedad civil en el proyecto integracionista, no hay que olvidar que el sistema legal ha institucionalizado la participación de la sociedad civil. Entonces, habría que preguntarse por el tipo de relación que establecen los espacios institucionalizados de la sociedad civil con cualquiera de los órganos del SICA que realiza la consulta ciudadana. En este sentido, la práctica y la normativa (Comité Consultivo del Sistema de la Integración Centroamericana [CC-SICA], 2007) muestran que son relaciones predominantemente de consulta, propuesta e incidencia sobre la política de la organización regional y el proceso de integración centroamericana con el alcance que precisa el Protocolo de Tegucigalpa (Sistema de Integración Centroamericana, 1991). A esto habría que agregar las relaciones de tensión y oposición que establecen las organizaciones que se mantienen al margen de dichos espacios institucionalizados (denominadas organizaciones outsider).

La preeminencia del carácter consultivo de la sociedad civil en el proceso integracionista ha sido objeto de crítica de algunas organizaciones civiles que participan en dichos espacios y de aquellas que han sabido aprovechar otras plataformas para realizar incidencia. Muchas de estas organizaciones de la sociedad civil demandan la participación en la toma de decisiones tal y como sucede en las políticas públicas en los ámbitos territoriales y nacionales de los países que la componen.

La sociedad civil centroamericana en el proceso de integración regional aparece, como ya dijimos, en calidad de actor emergente en los años 90, en un contexto donde están por un lado las políticas neoliberales condicionadas por el Fondo Monetario Internacional y el Banco Mundial que causan el debilitamiento del Estado, y por otro lado, ocurre el establecimiento de regímenes democráticos representativos y el apoyo técnico y económico y más aún, el reconocimiento de la sociedad civil como agente principal del desarrollo y la democracia por parte de los organismos internacionales, más la reactivación del proceso integracionista.

El interés de la sociedad civil por el proyecto integracionista aparece en el período 1992-1994 con el propósito de lograr la concertación entre las distintas redes regionales de sociedad civil para incidir en las decisiones llevadas a cabo sobre la integración regional. Los foros denominados Comité Centroamericano de Coordinación Intersectorial (1992) y la Iniciativa Civil para la Integración Centroamericana (1994) se constituyen en el antecedente del CC-SICA, el espacio consultivo de carácter general conformado en 1995. El funcionamiento de este espacio consultivo fue poco sistemático y organizado desde sus orígenes, cuestión que puede cambiar debido a que desde el año 2006 dispone del Plan de Acción para su fortalecimiento, gracias al apoyo financiero de la Unión Europea en el marco del Plan Apoyo a la Integración Regional (PAIRCA). El Plan de Acción para el fortalecimiento consultivo tiene tres ejes fundamentales: fortalecimiento gerencial, fortalecimiento orgánico y operativo y fortalecimiento estratégico. 
Las organizaciones civiles regionales que participan en el proyecto integracionista se caracterizan por ser heterogéneas: provienen de distintas nacionalidades, sectores y grupos e incluyen asociaciones civiles que pertenecen al ámbito económico, social; de origen común: surgen en respuesta a las políticas neoliberales que empiezan en los años 80; y autónomas del Estado (por ejemplo, el CC-SICA ha establecido criterios propios de autonomía y representatividad). Además, apuestan por un modelo de participación de doble vía: de abajo hacia arriba y a la inversa, como una manera de articular los espacios locales, nacionales y supranacionales. Asimismo, pese a su limitada estructura organizativa, han sabido utilizar las tecnologías de la información para comunicarse intragrupo y exponer posicionamientos o propuestas alrededor de procesos claves como la integración regional, la apertura comercial, el desarrollo y la democracia en la región, el rol de la cooperación internacional, los derechos humanos, el medio ambiente, la lucha contra la pobreza o la promoción de políticas sociales (Santos, 2010).

La capacidad de incidencia y propuesta de la sociedad civil regional en el proyecto integrador ha sido limitada por varias razones. Por un lado, las organizaciones civiles regionales tienen todavía una débil estructura organizativa, capacidad limitada de incidencia y participación en la esfera pública, carencias de capacitación técnica, falta de recursos económicos y apoyo institucional, y división de la sociedad civil en espacios formales e informales. Por otro lado, hay un escaso interés por parte de los gobiernos para considerar los planteamientos de la sociedad civil, actor al que se le adjudica el hecho de no ser representativo y al que se le ve como un receptor de políticas públicas. Además, en el proyecto integracionista, encontramos que se le otorga al CC-SICA el rol de asesor de la SG-SICA, instancia que no toma decisiones sino que tiene una función administrativa. A esto se suma el desconocimiento del proyecto integracionista por parte de las ciudadanías nacionales (Santos, 2010).

\section{Marco jurídico-institucional}

La participación de la sociedad civil en la estructura del SICA se ha dado a través de cuatro espacios consultivos de los distintos subsistemas que lo componen. El Protocolo de Tegucigalpa (Sistema de Integración Centroamericana, 1991) crea el Comité Consultivo del Sistema de Integración Centroamericana (CC-SICA) adscrito a la Secretaría General del SICA (SG-SICA); el Protocolo de Guatemala (Sistema de Integración Centroamericana, 1993) crea el Comité Consultivo de Integración Económica (CCIE) adjunto a la Secretaría de Integración Económica (SIECA); y la Cumbre Ecológica de Masaya (1995) crea el Foro de la Sociedad Civil de Ambiente y Desarrollo (FOSCAD) ${ }^{1}$ adscrito a la Comisión Centroamericana de Ambiente y Desarrollo (CCAD). También cuenta con un mecanismo de participación indirecta en el Tratado Marco de Seguridad Democrática (2001) a través de la SG-SICA y del CC-SICA. Aún está por conformarse el Comité Consultivo de Integración Social (CCIS) que ha dispuesto el Tratado de Integración Social (1995). El cuadro 1 presenta de forma esquemática los espacios de participación de la sociedad civil.

1 Cabe resaltar que el FOSCAD es un órgano en la órbita de la CCAD que no puede ser considerado como parte del sistema, ya que no está recogido en el marco jurídico. 
Cuadro 1. Espacios de participación de la sociedad civil en el SICA

\begin{tabular}{|c|c|c|c|c|c|}
\hline Subsistema & $\begin{array}{c}\text { Órgano/ } \\
\text { institución }\end{array}$ & $\begin{array}{c}\text { Condición } \\
\text { jurídica }\end{array}$ & Composición & Creación & Tipología \\
\hline Político & CC-SICA & Sistémica & Multisectorial & 1995 & Supranacional \\
\hline Económico & CCIE & Subsistémica & Sectorial & 2005 & Supranacional \\
\hline Ambiental & FOSCAD & Subsistémica & Multisectorial & 2004 & Supranacional \\
\hline Social & CCIS & Subsistémica & No creado & $\begin{array}{c}\text { No } \\
\text { creado }\end{array}$ & No creado \\
\hline $\begin{array}{c}\text { Educativo } \\
\text { cultural }\end{array}$ & No existe & No existe & No existe & No existe & No previsto \\
\hline
\end{tabular}

Fuente: Santos (2010, p. 550).

Los espacios consultivos de la sociedad civil antes descritos han tenido habitualmente poca trascendencia en el proceso de integración centroamericana, dado que la facultad consultiva no es obligatoria. Además, el comité consultivo general es el CC-SICA, compuesto por 27 organizaciones que proceden de diversos sectores (laboral, académico, grupos de población, empresarial, indígenas, afrodescendientes, etc.), mientras que el resto de los espacios consultivos tienen el carácter sectorial. El diseño y la construcción de estos espacios tienen problemas como la desarticulación y dispersión entre ellos, la ausencia de vínculos de jerarquización que terminan generando disfuncionalidad y tensiones entre los diversos actores que integran dichos espacios de participación. Finalmente, la independencia en la que se forja esta sociedad civil, unida a la falta de financiación por parte de las instituciones del SICA, a la heterogeneidad de intereses y al carácter federal de muchas organizaciones, termina dando lugar a actuaciones unilaterales y conductas erráticas, ofreciendo una imagen de desorganización e improvisación en torno a las actuaciones de estas organizaciones (Santos, 2009, p.67).

Por otro lado están las iniciativas regionales de organizaciones de la sociedad civil que hacen incidencia en el proceso de integración regional a través de su propia plataforma y de forma no permanente. Aquí encontramos la Iniciativa CID, la ALOP, la ASC. Estas organizaciones mantienen una actitud crítica sobre las políticas de desarrollo económico y social en detrimento de los sectores empobrecidos, aplicadas por los gobiernos de la región y su correspondiente equivalencia en el proceso de integración regional. El trasfondo del enfrentamiento es bastante complejo y se inserta dentro del debate ideológico (Santos, 2009, p.70).

Desde 2005 el CC-SICA dispone de capítulos nacionales, espacios que surgen de la necesidad de vincular al comité con aquellas organizaciones del ámbito nacional o local que por sus propias condiciones no podían formar parte del mismo. El Reglamento General para los Capítulos Nacionales (CC-SICA, 2010, p.1) define estos espacios como "instancias de apoyo y colaboración del Comité Consultivo, para contribuir en el ámbito nacional en el desarrollo de los espacios de reflexión, análisis y promoción de la integración centroamericana, con el fin de asegurar la participación e incidencia de los amplios sectores de la sociedad.” Los capítulos 
nacionales estarían conformados por las organizaciones nacionales miembros del CC-SICA en el ámbito regional y otras organizaciones nacionales y regionales residentes en el país que por su experiencia, conocimiento e interés en los temas del desarrollo y la integración centroamericana, puedan dar aportes para contribuir en propuestas calificadas dentro del marco del CC-SICA.

Aún cuando los capítulos nacionales están conformados en seis países de Centroamérica (con excepción de El Salvador), el seguimiento, la operatividad y la incidencia de los diferentes comités ha sido muy débil. En general se muestran con escasa capacidad propositiva. Además, la interrelación entre el CC-SICA y los capítulos nacionales ha sido coyuntural pese a que el Plan Estratégico del CC-SICA (2006) tiene como uno de los ejes estratégicos el fortalecimiento de estos espacios nacionales (Santos, 2010).

\section{Perfil del Foro de Mujeres para la Integración Centroamericana y la Iniciativa Mesoamericana por el Comercio, la Integración y el Desarrollo.}

El FMICA y la Iniciativa CID son actores civiles que se han venido fortaleciendo como actores regionales desde los años 90. El FMICA está integrado mayoritariamente por organizaciones de mujeres, aunque incluye también a miembras individuales. Lo componen asociaciones de mujeres indígenas, afro descendientes, sindicalistas, académicas, cooperativistas, productoras, empresarias, entre otras. Este Foro dispone de capítulos nacionales, lo que revela una amplia base social. La Iniciativa CID está conformada por federaciones, foros, cooperativas, ONG y movimientos sociales que tienen su área de influencia en países específicos.

Respecto a la estructura organizativa encontramos la tradicional Junta Directiva, Asamblea y mesas temáticas de trabajo en el caso del FMICA. Por su parte, la Iniciativa CID funciona con el esquema de co-coordinación, es decir, dos representantes de distintas organizaciones (actualmente uno por el Centro Humboldt de Nicaragua y otra por la Fundación Nacional para el Desarrollo de El Salvador) toman la decisión política y con el resto de miembros (un representante de cada organización de la sociedad civil que la integra) concretan la planificación estratégica, los planes operativos anuales, los análisis de coyuntura nacional y regional.

Las organizaciones civiles en estudio trabajan los temas nacionales con un enfoque regional. Las áreas temáticas de estas organizaciones son: comercio, integración y desarrollo sostenible (Iniciativa CID), integración centroamericana desde un enfoque de igualdad de género (FMICA). Más en concreto, los temas en los que ha trabajado la Iniciativa CID son derechos laborales, comercio, propiedad intelectual y medio ambiente. En el caso de FMICA han abordado los temas de economía y derechos laborales, migración y cambio climático desde la perspectiva de género.

La Iniciativa CID se caracteriza por el alto nivel de sus propuestas y un poco menos por acciones de incidencia política y formación. Ocurre lo contrario en el caso del FMICA que destaca por posicionar en la agenda de la integración las necesidades 
e intereses de las mujeres centroamericanas, sobre todo las más vulnerables.

El FMICA participa en los espacios institucionalizados de la sociedad civil en el SICA, a saber, el CC-SICA y los Capítulos Nacionales. La Iniciativa CID se opone a participar en este espacio consultivo regional. No obstante, muchas de sus organizaciones participan en los Capítulos Nacionales del CC-SICA. Además, hay organizaciones civiles que participan en la Iniciativa CID, en el FMICA y en los Capítulos Nacionales del CC-SICA. Es el caso de la Confederación Sindical de Trabajadores José Benito Escobar (que también es parte del CC-SICA) y el Centro Humboldt.

\section{Participación del FMICA y la Iniciativa CID en el proceso de integración centroamericana}

A continuación se describen los roles, intereses, acciones estratégicas, espacios y mecanismos de participación; factores facilitadores, oportunidades, limitantes y tensiones; así como los resultados alcanzados y los retos que tienen el FMICA y la Iniciativa CID para una participación protagónica en el proceso de integración centroamericana.

\subsection{Foro de Mujeres para la Integración Centroamericana}

El FMICA ha participado activamente en la elaboración y/o puesta en marcha de cinco importantes propuestas que contribuyen al proceso de integración centroamericana desde la perspectiva de igualdad de género. Cronológicamente, la primera consistió en la Agenda de Mujeres hacia la Integración Centroamericana (1997-1998), cuyo objetivo es "incorporar los intereses de las mujeres en la agenda de la sociedad civil e incidir en los Estados miembros, las instituciones y los órganos de la integración centroamericana" (Vanderschaeghe, 2010, p.8). Dicha agenda es considerada una guía para las actividades de incidencia política, negociación y cabildeo de las mujeres centroamericanas y contiene temas económicos, políticos, sociales-culturales e inclusive ambientales.

A finales de la década de los años 90, en el marco de la reconstrucción post Mitch de Centroamérica, y en calidad de miembro del CC-SICA y de la Iniciativa Civil para la Integración Centroamericana (ICIC), el FMICA promovió la incorporación de la dimensión de género en los planes y programas que los estados centroamericanos propusieron a la cooperación internacional en Estocolmo y Madrid. Además, pretendieron incidir en el destino de los recursos.

En el período 2003-2010, el FMICA participa en el Programa Agenda Económica de las Mujeres (AGEM) (Programa de las Naciones Unidas para el Desarrollo, s.f.). Dicho programa se propone aportar instrumentos y herramientas que permitan generar y potenciar las capacidades de análisis con perspectiva de género en el tema de la macroeconomía en un contexto de integración centroamericana y apertura económica. Se trata de una agenda que ha sido debatida por la academia, instituciones del gobierno central, organizaciones de la sociedad civil y la cooperación internacional y ha logrado la incorporación de dichos temas 
en las agendas económicas regionales y nacionales (Martínez, s.f.).

En 2004 el FMICA, junto con el resto de organizaciones del CC-SICA, diseñaron el plan de fortalecimiento de este espacio consultivo que busca generar condiciones políticas institucionales y presupuestarias para el desarrollo y posicionamiento de ese organismo. Uno de los resultados fue la conformación de los capítulos nacionales del CC-SICA en todos los países de la región centroamericana, a excepción de El Salvador (Martínez, s.f.).

Más recientemente, el FMICA elaboró la Agenda de Equidad de Género ante el Acuerdo de Asociación Unión Europea - Centroamérica. La agenda contiene propuestas en cada uno de los tres pilares del acuerdo: diálogo político, cooperación y comercio.

A partir de 2008 el FMICA trabaja el tema de cambio climático. Realizó un diagnóstico sobre Mujer y Cambio Climático en la Región Centroamericana y ha diseñado una propuesta frente a este fenómeno desde la perspectiva de las mujeres. Por ahora, el camino es presentar la propuesta ante los Ministros de Ambiente y de los Recursos Naturales de cada país, y a nivel regional ante la Comisión Centroamericana de Ambiente y Desarrollo (CAAD), de tal manera que puedan incorporar las propuestas del FMICA en la estrategia regional de cambio climático.

Las estrategias del FMICA para ejercer ciudadanía en la integración centroamericana han sido dos. La primera consiste en ser parte del CC-SICA y los Capítulos Nacionales del CC-SICA y la otra estrategia está relacionada con el trabajo de lobby, la interlocución con los tomadores de decisiones: autoridades gubernamentales, funcionarios del SICA y de la cooperación internacional, para intercambiar información y/o presentar propuestas.

Tres han sido los espacios a través de los cuales el FMICA ha posicionado el tema de la igualdad de género y los derechos humanos de las mujeres a nivel regional. Participa en el CC-SICA y los Capítulos Nacionales del CC-SICA asumiendo un rol directivo o como un miembro más. También asiste al Programa Regional de la Agenda Económica de las Mujeres (Programa de las Naciones Unidas para el Desarrollo, s.f.). A futuro, el FMICA podría articularse con el Consejo de Ministras de la Mujer de Centroamérica (COMMCA), instancia creada para articular los esfuerzos de las instituciones gubernamentales que dirigen las políticas de género para la equidad en la región.

Los factores que han facilitado la participación activa del FMICA en el proceso de integración regional son: enfoque feminista en el tratamiento de los temas regionales, alto compromiso de las organizaciones miembros a pesar de disponer de pocos recursos económicos, capacidad para definir las estrategias de incidencia, capacitación de las organizaciones miembros en género y economía a través de diplomados financiados por la AGEM y en talleres de capacitación sobre integración centroamericana, tratados de libre comercio, derechos laborales y cambio climático.

Entre las oportunidades están: alianzas dentro del CC-SICA con el sector sindical e indígena, con el Movimiento Cooperativo y a veces con el Consejo Superior de las Universidades (CSUCA); intercambio de información sobre la agenda regional con funcionarios de gobierno de los países centroamericanos y de la cooperación internacional; apoyo de algunas organizaciones mixtas en los países 
donde tiene presencia el FMICA; reconocimiento del trabajo realizado por el Comité Económico y Social Europeo (CESE) y la existencia de la AGEM y la Agenda de las mujeres hacia la Integración Centroamericana como dos plataformas para la incidencia construidas desde diferentes espacios y expresiones de las organizaciones de mujeres centroamericanas.

Los factores obstaculizadores de la incidencia del FMICA podemos ubicarlos en dos niveles: las limitaciones a nivel de su funcionamiento interno y las dificultades con relación a otros actores (Movimiento de Mujeres, gobiernos de los países centroamericanos). A nivel interno tenemos: pocos recursos económicos y humanos para conseguir un alto nivel de propuesta; falta de infraestructura del Foro que sirva como referente (funciona de forma rotativa en las oficinas de las organizaciones miembros); escaso tiempo disponible de las representantes de organizaciones que la integran, lo que redunda en que las mesas temáticas nacionales y regionales del FMICA se activen según la coyuntura; escasa divulgación de los resultados alcanzados; insuficiente representación de las mujeres empresarias; dinamismo diferenciado de los capítulos nacionales del FMICA (los más beligerantes son FMICA Nicaragua y Guatemala) debido a los contextos de cada país, los liderazgos, recursos económicos y experiencia de que disponen las organizaciones que la integran.

Otras limitantes del FMICA son: prevalencia de la cultura patriarcal en la mayoría de los tomadores de decisiones a nivel local, nacional y regional; algunas corrientes del movimiento de mujeres rechazan la interlocución con los tomadores de decisión de la integración centroamericana; débil articulación del COMMCA con el Foro; la mayoría de los liderazgos de las organizaciones de sociedad civil regional representadas en el CC-SICA son masculinos.

Una de las tensiones más recientes que experimentó el FMICA como parte del CC-SICA fue con una parte del sector empresarial y tiene que ver con la reelección del líder sindical Carlos Molina como presidente del directorio del CCSICA. Dijeron estar en desacuerdo con los procedimientos (cambio de estatutos del CC-SICA) para la reelección y que los logros del CC-SICA son colectivos y no individuales, por lo tanto, no se presentaron a la Asamblea para la elección de la junta directiva.

También hay conflictos que devienen de la concepción y naturaleza misma de la integración regional, pues los mecanismos y los espacios de toma de decisión han sido concebidos desde una visión intergubernamental, dejando a las organizaciones de sociedad civil relegadas. Una muestra de ello fue el Acuerdo de Asociación entre la Unión Europea-Centroamérica (AdA) cuando, en ocasiones, la participación del CC-SICA fue rechazada.

Otra limitante es que entre las organizaciones civiles y el sector empresarial hay desconfianza. Esto se puso de manifiesto con el AdA cuando el Comité Consultivo de Integración Económica pidió al Comité Económico y Social Europeo, hacerse cargo del pilar económico. Además, el FMICA alega que los empresarios siempre tienen espacios privilegiados dentro del SICA y disponen de alianzas con funcionarios de Gobierno y partidos políticos para hacer prevalecer sus intereses.

Respecto a los resultados que ha tenido el FMICA, los podemos ubicar en tres niveles: en el ámbito interno de la organización, como miembro del CC-SICA y desde el CC-SICA. A nivel interno, uno de los resultados ha sido la apertura al 
cambio con relación a los temas que tradicionalmente han sido parte de la agenda de las mujeres. Han definido propuestas concertadas que vinculan los temas económicos con la defensa de los derechos políticos y sociales de las mujeres. Ha incrementado las capacidades técnicas, organizativas y propositivas, aunque todavía hace falta. También estimuló la dinámica local de las organizaciones miembros del FMICA y promovió la creación de las oficinas para la mujer en los ministerios de trabajo en los estados nacionales de Centroamérica.

Dentro del CC-SICA el FMICA ha logrado un reconocimiento por haber impulsado, junto a otros actores, la dinamización del CC-SICA y de los Capítulos Nacionales en países como Nicaragua y Guatemala. Desde el CC-SICA introdujo la perspectiva de género en la integración centroamericana más allá de la mirada sectorial o temática. Además, consiguió el posicionamiento de la Agenda de Género en el proceso de negociación del AdA. Esto provocó que la Unión Europea denomine estratégico al tema de género, tópico rara vez considerado en los acuerdos de este tipo.

El FMICA tiene desafíos relacionados con su dinámica interna y la articulación con otras organizaciones de mujeres, instituciones del SICA y Estados Nacionales.

Al FMICA le hace falta profundizar en el posicionamiento de las mujeres en procesos regionales, en el nivel de propuesta, de tal manera que se complemente el tema político con el económico y tengan un carácter más técnico. Para esto, las entrevistadas mencionaron que era importante crear posibles alianzas con las universidades y la Iniciativa CID. Se requiere trabajar más lo relacionado con la dimensión económica: el empleo de las mujeres, el acceso al crédito, definir el monitoreo del AdA. Es necesario el fortalecimiento y sostenibilidad económica del Foro para hacerlo más operativo, con recursos técnicos a tiempo completo, con la infraestructura y equipamiento necesarios y con la comunicación más estrecha de sus integrantes (mínimo, dos a tres encuentros anuales). Es necesario definir un programa de formación en equidad de género y comercio, y en análisis de coyuntura, dirigido a afiliadas de los capítulos nacionales del FMICA. Habrá que divulgar las propuestas y resultados del FMICA de tal manera que llegue a las mujeres y tomadores de decisiones en la región centroamericana.

El fortalecimiento de los capítulos nacionales del FMICA es una tarea pendiente. Eso implica incorporar más organizaciones de mujeres, incluyendo las denominadas en resistencia; pero también a la juventud y mujeres de la gran empresa.

Las instituciones del SICA consideran pertinente que el FMICA dinamice los capítulos nacionales del CC-SICA en todos los países de la región centroamericana. La incidencia en la elección del directorio del CC-SICA para que haya representación equitativa entre hombres y mujeres sigue siendo importante. Apuestan a establecer alianzas y coordinaciones con el COMMCA y los ministerios o secretarías de la mujer de los estados centroamericanos (quizás esa articulación debería reglamentarse para que el COMMCA lo asuma como una competencia y una oportunidad de contribuir a la democratización del proceso de integración). La interrelación con el COMMCA permitiría reconocer cómo se pueden traslapar las distintas agendas de las mujeres; la que tiene el FMICA: Agenda de Mujeres hacia la Integración Centroamericana; la que ejecuta UNIFEM: Agenda Económica de las Mujeres; y la que el COMMCA está definiendo. 
Sensibilizar y capacitar a los tomadores de decisión a escala nacional, regional e internacional acerca de la representación de las mujeres en los espacios públicos y la importancia de la perspectiva de género en las propuestas (de índole político, social, económico y cultural), y la ejecución y monitoreo de las políticas públicas.

Con relación a los retos que tiene la sociedad civil organizada en general, frente al proceso de integración regional, las entrevistadas del FMICA revelaron que los actores civiles centroamericanos deben demandar y proponer la transformación del SICA de tal manera que trabaje en función de los intereses de la mayoría y el desarrollo de las comunidades. El CC-SICA, debe elevar el nivel técnico de las propuestas de tal manera que no se limite únicamente al posicionamiento políticoideológico. Además, debe de involucrar con mayor fuerza a las universidades para que incorporen en sus currículos, en sus investigaciones y propuestas el tema de la integración centroamericana, y se logre desarrollar una identidad y ciudadanía centroamericana.

\subsection{Iniciativa Mesoamericana de Comercio, Integración y Desarrollo Sostenible}

La Iniciativa CID ha asumido desde sus orígenes, a finales de los años noventa, el tema de la integración y el desarrollo regional como un reto prioritario, reconociendo que había sido un proceso que no representaba a los sectores más vulnerables de la región.

Partiendo de que en Centroamérica prevalece un regionalismo abierto, impulsado por los gobiernos, y que no se cuenta con una estrategia de desarrollo regional, la Iniciativa CID se ha propuesto incidir en la toma de decisiones y contribuir a impulsar el desarrollo sostenible y equitativo a través de la investigación, capacitación, sensibilización, formulación de propuestas, cabildeo, incidencia política y articulación con otras redes y foros. En términos generales ha fungido como un interlocutor entre la sociedad civil y las instancias de decisión del sistema integracionista.

A pesar del propósito declarado de la Iniciativa CID de trabajar en el proceso de integración regional, ésta ha sido una instancia que desde sus inicios se ha mantenido al margen de las instituciones y espacios oficiales de la integración, pues sus miembros consideran que no representan las necesidades de la mayoría de la población. En ese sentido, han planteado demandas sectoriales emanadas de actores civiles ante instancias de toma de decisiones y diversos sectores influyentes a través del cabildeo, la incidencia política e incluso las acciones de presión.

El actor civil en estudio ha participado activamente en los dos procesos de negociación de los tratados comerciales de Centroamérica con Estados Unidos y Europa. En relación al tratado comercial bilateral con Estados Unidos, la Iniciativa CID tuvo un papel protagónico en las rondas de negociación a través de su presencia en el Cuarto Adjunto. Por el contrario, el CC-SICA tuvo un bajo perfil porque en la práctica aún no se le había reconocido como órgano del sistema. Esta realidad cambió en el proceso de negociación del AdA al conferírsele al CC-SICA el rol de interlocutor oficial con su homólogo europeo, el CESE. A partir de este contexto, se nutre más el espacio de diálogo entre la Iniciativa CID y el CC-SICA, particularmente 
a través de los Capítulos Nacionales.

Para concretar sus roles, la Iniciativa Mesoamericana ha implementado las estrategias siguientes:

- Exigencia del derecho a la información pública como uno de los niveles básicos para la participación ciudadana.

- Comunicación efectiva entre las organizaciones participantes.

- Posicionamiento de propuestas y aportes de las organizaciones civiles al proceso de formulación de las políticas públicas referidas a la democratización del comercio y la integración.

- Participación y articulación activa en diferentes espacios de negociación e incidencia nacional y regional y monitoreo permanente de su efectividad.

- Investigación y evaluación de impacto de la implementación de los acuerdos comerciales en la región, además del seguimiento de las respectivas agendas complementarias (Iniciativa CID, 2002, p.3).

Otros factores que han favorecido el alcance de los propósitos planteados son: participación voluntaria y alto compromiso personal de sus miembros; capacidad para definir estrategias de incidencia y de cabildeo; mantiene su autonomía respecto al SICA; ha impulsado programas de formación sobre los temas de integración centroamericana, tratados de libre comercio, derechos laborales, género, entre otros. Se suma a ello el nivel de especialización de las organizaciones miembros, y las capacidades y experiencias organizativas de sus líderes, lo que permite elaborar investigaciones y propuestas con un alto nivel técnico.

Una de las oportunidades más importantes de incidencia fue el trabajo combinado de la Campaña ante el Tratado de Libre Comercio entre Estados Unidos y Centroamérica, que le permitieron posicionarse como un interlocutor a nivel de cúpula entre las partes negociadoras y de vaso comunicante con ciertos sectores de la sociedad civil. Actualmente, el seguimiento de la Agenda Complementaria emanada del CAFTA constituye otra posibilidad de seguir dando aportes a estos procesos regionales a pesar de las limitaciones y de la rigidez de los esquemas y mecanismos de negociación de los tratados comerciales. Además, y aunque con sus particularidades, el proceso del Acuerdo de Asociación representó otra coyuntura para hacer propuestas.

Otras oportunidades que favorecen la labor de la Iniciativa CID, son las alianzas tejidas con algunas organizaciones regionales y continentales, tales como Alianza Social Continental, Confederación Centroamericana del Trabajo, Centro América por el Diálogo, Alianza el Corredor del Diálogo, Asociación Latinoamericana de Organizaciones de Promoción (ALOP). También está el intercambio de información con funcionarios de gobierno de los países centroamericanos y de la cooperación internacional y con los capítulos nacionales del CC-SICA.

Desde la perspectiva de la Iniciativa CID, los principales factores que dificultan la participación de la sociedad civil en el proceso de integración son los siguientes:

- Ausencia de una identidad centroamericana sumada a un débil ejercicio de la ciudadanía que se refleja a nivel regional en el tipo de participación.

- Los gobiernos de la región han reducido las estrategias de desarrollo a simples estrategias de inserción externa que no son condiciones suficientes para impulsar el desarrollo de los países centroamericanos. 
- La dinámica de la integración regional está divorciada de los procesos y de los actores estratégicos de la región y no está respaldada por mecanismos institucionalizados de toma de decisiones.

- Rol limitado del CC-SICA como mecanismos de participación de la sociedad civil que asegure el acceso a los procesos donde se toman las decisiones fundamentales de la integración regional.

- Existencia de un clima de desconfianza y preocupación entre gobiernos, partidos políticos, empresarios y corporaciones hacia las organizaciones civiles, ante un eventual monitoreo de los acuerdos.

- La polarización en el seno de la sociedad civil en torno a la posición frente a los acuerdos comerciales y la integración regional ha tenido como consecuencia la incapacidad de articular y complementar posiciones distintas y la incidencia ha sido limitada.

A pesar de que la Iniciativa CID no ha sido miembro de instancias formales de participación en el sistema integracionista, ha contribuido a democratizar la agenda de la integración, formular y gestionar propuestas de algunos sectores e incidir en las negociaciones del tratado de libre comercio entre Estados Unidos y los países de Centroamérica y recientemente en el proceso del AdA.

La democratización de la agenda regional supuso incorporar los temas de medio ambiente, desarrollo agropecuario, pesca, propiedad intelectual, derechos laborales, entre otros. Para ello han involucrado a productores, pescadores, mujeres, etc.

En el marco de las negociaciones del CAFTA-DR incorporaron temas complementarios y se impulsaron propuestas orientadas a la protección de ciertos sectores de la economía local. De igual forma impulsaron leyes cuya finalidad era "contar con un proceso de reformas y de armonización de normativas; contribuir a eliminar factores negativos que se puedan definir como barreras no arancelarias; lo que permitiera a los países participar y aprovechar un acuerdo comercial, sin tener que utilizar el mecanismo de solución de controversias" (Iniciativa CID, 2004, p. 8).

Con relación al Acuerdo de Asociación, lograron que el tema ambiental fuera vinculante y que los estándares se fijaran sobre la base de los parámetros más exigentes de la región. En términos laborales, y en el caso de Nicaragua, se consiguieron avances en la legislación con relación a la seguridad e higiene ocupacional, la seguridad social y la creación del Consejo Nacional del Trabajo. A esto se agrega que impulsaron instancias de monitoreo con la participación de representantes de la sociedad civil.

Para seguir fortaleciendo su protagonismo, uno de los retos de la Iniciativa CID es garantizar la sostenibilidad financiera para disponer de los recursos necesarios y ejecutar la agenda de trabajo a nivel local, nacional y regional, sobre todo en un contexto en el que las prioridades geográficas, temáticas y políticas de las agencias cooperantes han experimentado cambios significativos. Esta situación representa un enorme desafío, dado que hay muchas prioridades de la agenda complementaria derivada de los tratados comerciales, la cumbre del cambio climático, el proceso de gestión de una política regional sobre soberanía alimentaria, entre otros; lo que constituye un trabajo escalonado con dinámica compleja, personal calificado, un amplio espectro de actores civiles, en fin, procesos muy costosos que requieren suficientes recursos. 
Aunque no existe consenso a lo interno de la Iniciativa CID, algunos miembros consideran que dicha organización debe ampliar su membrecía, es decir, incluir a otros sectores de la sociedad civil, además de articularse con otras redes que tienen un trabajo de base más amplio. Esto requeriría un proceso de consolidación interno en torno a posiciones ideológicas.

Otro desafío de la organización civil outsider, es canalizar sus propuestas y demandas en el marco de los distintos procesos de integración, aunando esfuerzos para fortalecer y reorganizar mejor los mecanismos formales de participación, conscientes de los alcances reales de la integración en Centroamérica.

\section{Conclusiones}

La reactivación de la integración centroamericana a inicios de los años noventa supuso la institucionalización de la participación de la sociedad civil, primero en el CC-SICA y luego en el resto de los comités consultivos de carácter sectorial (CCIE, FOSCAD). Algunas organizaciones civiles se han incorporado en dichas estructuras institucionales, mientras que otras participan desde espacios fuera del sistema y sin la sistematicidad que se requiere.

Los espacios consultivos de la sociedad civil han tenido poca incidencia en las principales decisiones de la región dado que la facultad consultiva no es de obligado cumplimiento (Sistema de Integración Centroamericana, 1991). Por otro lado, algunos gobiernos han concedido poca atención a la participación ciudadana debido a que ha primado una visión de la sociedad civil como sujeto receptor de políticas públicas que emanan de acuerdos regionales y debido a la cuestionada credibilidad de la naturaleza representativa de la sociedad civil ante la clase política.

Las organizaciones civiles han debatido acerca de su legitimidad, representatividad, financiación y la profundidad de los análisis y propuestas frente al proceso de integración regional. De estas discusiones han sido objeto el FMICA y la Iniciativa CID. El FMICA es una organización con base social que no ha logrado reunir a la pluralidad de organizaciones de mujeres porque mientras que para algunas es pertinente la interlocución con los gobiernos y la participación en el CC-SICA y en los Capítulos Nacionales, otras mantienen una desconfianza y oposición abierta a los gobiernos. Además, es un actor civil que registra déficit de financiamiento y tiene el reto de garantizar un alto nivel de propuesta. La Iniciativa CID reúne a un conjunto de organizaciones especializadas en distintas temáticas regionales sin que la mayoría tenga una amplia base social y con poca posibilidad de que sus propuestas de alto nivel sean retomadas por el SICA.

Las organizaciones en estudio se han caracterizado por abordar temas económicos, ambientales y sociales: Tratado de Libre Comercio de los países de Centroamérica con Estados Unidos, Acuerdo de Asociación entre la Unión Europea y Centroamérica, derechos laborales, propiedad intelectual, cambio climático, perspectiva de género en la integración regional, entre otros tópicos.

El FMICA participa activamente en los espacios institucionalizados de la sociedad civil: CC-SICA y los Capítulos Nacionales. La Iniciativa CID, a pesar de resistirse a integrar el CC-SICA, participa a través de sus organizaciones 
en los Capítulos Nacionales. En este sentido, hay una contradicción entre las organizaciones de la CID desde el punto de vista político-ideológico, en tanto que los Capítulos Nacionales se definen como "instancia de apoyo y colaboración del Comité Consultivo, para contribuir en el ámbito nacional en el desarrollo de los espacios de reflexión, análisis y promoción de la integración centroamericana, con el fin de asegurar la participación e incidencia de los amplios sectores de la sociedad" (CC-SICA, 2010, p.1).

La participación del FMICA y de las organizaciones civiles que conforman la Iniciativa CID en estructuras institucionalizadas o no institucionalizadas parte del carácter autónomo de las organizaciones y puede estar reflejando la complejidad de los intereses y acciones estratégicas de este actor; pero también podría representar la falta de una visión concreta sobre la trayectoria que debe de tener la sociedad civil respecto al proceso de integración regional. No hay que olvidar que el CC-SICA, en tanto comité consultivo global o general es un actor que recientemente ha logrado reconocimiento como órgano del sistema.

Las organizaciones en estudio apenas comienzan a desempeñar un rol protagónico en el proceso de regionalización. El FMICA tuvo un rol beligerante en la dinamización del CC-SICA y la creación de los capítulos nacionales y logró, desde el CC-SICA, posicionar el enfoque de género en las instituciones del sistema. La Iniciativa CID, con su elevado nivel de investigación, propuesta e incidencia, consiguió que se incorporaran intereses de los sectores pesca y temas importantes como los derechos laborales y socio-ambientales.

La sociedad civil regional debe de aprovechar el espacio creado en la estructura institucional del SICA. La participación desde espacios fuera del SICA poco ayuda al protagonismo de este actor dentro de las discusiones centrales de la integración regional. Las fortalezas del FMICA, de la Iniciativa CID y del resto de organizaciones del CC-SICA seguramente tendrían un mayor potencial para garantizar el posicionamiento político y un alto nivel de propuesta de la sociedad civil centroamericana. También pudieran lograr que la consulta de la sociedad civil sea de carácter obligatorio e incluso participar más allá de la consulta, en la toma de decisiones de las políticas públicas regionales tal como lo demandan ambas organizaciones civiles.

\section{Referencias bibliográficas}

Cohen, J. L. \& Arato, A. (2000). Sociedad Civil y Teoría Política. México: Fondo de Cultura Económica.

Comité Consultivo del Sistema de la Integración Centroamericana. (2010). Reglamento General para los Capítulos Nacionales. El Salvador: Autor.

Comité Consultivo del Sistema de la Integración Centroamericana. (2007). Estatuto Consultivo del Comité Consultivo del Sistema de la Integración Centroamericana CC-SICA. Managua: Autor.

Iniciativa CID. (2002). Iniciativa Mesoamericana de Comercio, Integración y Desarrollo Sostenible. Documento Institucional. San Salvador: Autor.

Iniciativa CID. (2004). Desafios y propuestas para el sector a mbiental, laboral y agropecuario 
de Nicaragua ante la firma del CAFTA. Documento Preliminar. Managua: Autor.

Martínez, J. E. (s.f.). La Institucionalidad de la Integración Económica Centroamericana: Oportunidades para la Agenda Económica de las Mujeres. Libro de Trabajo. Managua: UNIFEM, PNUD, Asdi.

Ortega, M. (2008). La relación gobierno-sociedad civil en el actual contexto. Managua: FONG-INGES.

Programa de las Naciones Unidas para el Desarrollo Nicaragua (s.f.). La Agenda Económica de las Mujeres. Recuperado el 12 de junio de 2010, de http://www. undp.org.ni/proyectos/5/33

Santos Carrillo, F. R. (2010). La Integración Regional Centroamericana y la Participación de la Sociedad Civil. Disertación Doctoral no publicada, Universidad de Córdoba, España.

Sistema de Integración Centroamericana. (1991). Protocolo de Tegucigalpa a la Carta de Organización de Estados Centroamericanos (ODECA). Recuperado el 16 de abril de 2010, de http://www.sica.int/busqueda/busqueda_basica.aspx?idCat=\&i $\mathrm{dMod}=3 \& \mathrm{IdEnt}=1 \& \mathrm{Pag}=7$.

Sistema de Integración Centroamericana. (1993). Protocolo al Tratado General de Integración Económica Centroamericana (Guatemala). Protocolo de Guatemala. Guatemala: Autor.

Vanderschaeghe, M. (2010). La voz del FMICA en el Acuerdo de Asociación con la Unión Europea: Una experiencia de incidencia desde las mujeres. Managua: Centro Editorial de la Mujer. 